\title{
Factors That Impact End-of-Life Decision Making in African Americans With Advanced Cancer
}

\author{
Cathy L. Campbell, PhD, APN-BC, \\ Assistant Professor, University of Virginia, School of Nursing, Charlottesville
}

Ishan C. Williams, PhD, and

Assistant Professor, University of Virginia, School of Nursing, Charlottesville

Tamara Orr, PhD, RN, LCP

Affiliate Professor, Virginia Commonwealth University School of Nursing and is Clinical Health Psychologist, Massey Cancer Center, Richmond

\begin{abstract}
Significance-African Americans with cancer are less likely to use hospice services and more likely to die in the hospital than white patients with the same diagnosis. However, there is much that is not understood about the factors that lead African Americans to choose options for end-oflife care.
\end{abstract}

Design-A qualitative, descriptive design was used in this pilot study.

Methods-Interviews were conducted with two groups of African Americans with advancedstage cancer (people enrolled in hospice and those who were not under hospice care).

Findings-End-of-life decisions were primarily guided by clinical factors, the patient-related physical, emotional, and cognitive symptoms that are sequelae of the underlying disease or medical treatments. The physician was the healthcare provider most likely to be involved in decision making with patients, family members, and caregivers. Individual factors, such as personal beliefs, influenced end-of-life decision making. Religion and spirituality were a topic in many interviews, but they did not consistently influence decision making.

Discussion-Future studies should include interviews with family members, caregivers, and healthcare professionals so that factors that impact end-of-life decision making can be fully described. Strategies to facilitate recruitment will need to be added to future protocols.

\section{Keywords}

African Americans; decision making; hospice; qualitative research

\section{BACKGROUND}

To date, the hospice and palliative care literature has highlighted a disparity in the use of hospice services between African Americans and whites. African Americans are less likely to use the services of hospice than whites with the same diagnosis because of a number of factors. Many African American communities find that hospice's tenet of embracing death

Address correspondence to Cathy L. Campbell, PhD, APN-BC, 202 Jeanette Lancaster Way, Charlottesville, VA 22903-3388 (clc5t@virginia.edu).

The content is solely the responsibility of the authors and does not necessarily represent the official views of the National Institute of Nursing Research or National Institutes of Health. 
as a natural occurrence is philosophically incompatible with faith in God's omnipotence and the desire to "affirm life at all costs."1-3 This body of literature provides valuable information about the utilization of hospice by African Americans; however it does not fully describe factors that might impact decision making.

African Americans are more likely than whites to die in the hospital, ${ }^{4}$ and unfortunately, deaths in acute-care settings are sometimes characterized by long periods of futile, lifesustaining treatment; inadequate pain management; and poor communication with the healthcare team. ${ }^{5}$ Hospice care is only one end-of-life (EOL) choice. There are many decisions that may be considered for EOL care including changing treatment regimens, stopping anticancer treatment (radiation or chemotherapy), starting palliative treatment, selecting the place of care, choosing to elect or decline artificial nutrition and hydration, and considering other means of life support. ${ }^{6-8}$ Little has been written about the factors that impact EOL decision making for African Americans considering hospice or other choices for EOL care.

\section{Conceptual Framework}

African Americans with advanced cancer and their families may consider many factors during the process of EOL decision making. Clinical, individual, and social factors are among the most salient factors that have an impact on decision making for any person with advanced cancer. Clinical factors (defined as the patient-related physical, emotional, and cognitive symptoms due to the underlying disease, medical treatments, or medications used in the plan of care) are the most significant factors. ${ }^{9}$ The clinical factors guide the physician's plan of care, and a decline in a patient's physical status (ie, growth in tumor size, increased symptom burden) is often the catalyst to initiate discussions about EOL decision making. ${ }^{6}$ Second, individual factors, such as personal values, subjective evaluations of quality of life, ${ }^{10}$ and religion and spirituality, can also impact EOL decision making. The philosophy of "affirming life at all costs" is valued in many African American communities. ${ }^{1,11}$ Consistent with this philosophy, African Americans are less likely to complete advance directives. ${ }^{1}$ Third, social factors may impact EOL decision making. Social factors include the involvement of family members, caregivers, other significant people, and healthcare professionals in decision making. ${ }^{12}$ Decision making in African American families is family centered. ${ }^{1}$ Family members, caregivers, and fictive kin (ie, play daughter) often play a role in the decision-making process, participating in the discussion of options, evaluating options, or providing feedback about decisions.

To develop interventions to increase access to compassionate EOL care for African Americans, we must understand more about the factors that lead African Americans to choose options regardless of the setting of care. ${ }^{1}$ The Hospice and Palliative Care Nurses Association affirms that supporting decision making is a significant nursing intervention. ${ }^{13}$

In response to this gap in the knowledge base, the pilot study was guided by the following research question: What individual, clinical, and social factors influence African Americans who have been diagnosed with a life-limiting illness to choose hospice or other options for EOL care?

\section{METHODS}

A qualitative, descriptive design was used to explore the factors that influenced EOL decision making for African Americans. 


\section{Sample}

Seven people with advanced cancer were enrolled in the study. Eligibility criteria were having any type of cancer (stage III or IV), being 50 years or older, English speaking, having willingness and ability to discuss the experience of living with a life-limiting illness without emotional distress, and having the cognitive and the physical stamina to participate in two interviews, if needed.

The study was approved by the institutional review boards (IRBs) at the University of Virginia, Virginia Commonwealth University, Augusta Medical Center (Fishersville, VA), and a community hospice provider. Augusta Medical Center's IRB provided the review for one of the community hospice providers, and the second hospice provider had its internal review committee approve the proposal.

\section{Recruitment Plan}

Two methods were used to recruit people for the study. The primary investigator (PI) presented the purpose of the study, eligibility requirements, the data collection methods (semistructured interview and medical record review), and a copy of the interview guide to healthcare providers (HCPs). The full protocol was available for review upon request. The HCPs were from two hospice programs in central Virginia, an adult hematology/oncology team from a cancer center in central Virginia, and an outpatient rural cancer clinic affiliated with another university-affiliated cancer center. The study was also advertised to the general public by posting flyers in the community, placing advertisements in local newspapers and an electronic community bulletin board, by sending out press releases to the media, and by participating in an interview recorded for a radio show (the transcript from the show was posted online also). For participants who called in response to advertisement to the general public (ie, were not referred by their $\mathrm{HCP}$ ) met the study criteria and indicated a desire to participate in the study, the potential participant was requested to sign the physician eligibility form. The physician eligibility form gave the physician permission to release information about study eligibility to the research team.

\section{Managing Emotional Distress}

The HCP making the referral determined study eligibility, including the ability to discuss EOL topics without emotional distress. Two major strategies were built in to the research protocol to address emotional distress, if it occurred. Given that discussion of death and dying topics could cause emotional upset, ${ }^{3,14,15}$ we had an IRB-approved plan to contact the HCP for further evaluation and follow-up of emotional distress or physical symptom exacerbation. For participants who were not enrolled in hospice, the patient's physician or on-call service was contacted. For participants enrolled in hospice, the hospice clinical manager was called directly during day, and the on-call staff was contacted after 5:00 PM and on the weekends. Second, all of the interviews were conducted by the primary author (C.L.C.), who is an experienced, doctorally prepared nurse. She has worked with people with advanced cancer and their families in hospice for 19 years as a direct care provider, manager, and researcher in rural and urban settings. ${ }^{15,16}$ This plan had been used in prior research with a similar population by the primary author (C.L.C.). ${ }^{3}$ There were no adverse events for emotional distress in the current study.

Nineteen people were referred to the study by a HCP or contacted the PI to inquire about the study. The PI screened each person and found that 12 of the 19 people screened did not meet the inclusion criteria. Most people who did not meet the criteria were those who had called in response to the advertisements to the general public. The most common reason for not meeting the study eligibility criteria was having a noncancer diagnosis. Thus, seven people 
met the study eligibility criteria and enrolled in the study. All participants provided informed consent prior to data collection.

Data were collected during face-to-face audio-taped interviews with the first author (C.L.C.). The original protocol included a clinical record review by the PI to collect data to confirm the primary diagnosis. As additional sites were added, it became more challenging to access clinical records. For example, some of the agencies used paper charts, while another was transitioning to electronic medical records. Therefore, after the first four participants, only HCPs who made referrals to the study reviewed the clinical records for the study eligibility criteria. Demographic information was collected, and functional status was measured using the Karnofsky Performance Status (KPS) score. The KPS determines an individual's ability to perform activities of daily living, work outside the home, and the frequency of seeking medical care. ${ }^{17}$ Total scores range from 0 to 100 , with higher scores indicating better functional status. The KPS is also used to estimate likelihood of survival for most serious illnesses, including advanced cancer (the lower the score, the less likelihood of survival). ${ }^{17}$ The KPS is a tool with well-established validity and reliability in people with advanced cancer and enrolled in hospice. Mor et al ${ }^{18}$ reported strong construct validity $(0.49)$ with measures of physical functioning when using the KPS in a population of adult hospice patients with cancer. Moderate interrater reliability (0.69), test-retest reliability (0.66), and moderate construct validity with physical functioning (ranging from $0.40-0.63$ ) were reported by researchers using the KPS in a sample of patients with advanced cancer. ${ }^{19}$

Interviews were conducted either at the home of the participant or in a private room at the clinic. Interviews were facilitated by an interview guide designed to elicit discussion about the factors (clinical, individual, and social) that led to EOL decisions and to identify the steps that may have led to the choice of hospice, if that had been chosen by the participant. The interview guide was adapted from a version developed by Gauthier ${ }^{8}$ to study decision making in an elderly population enrolled in hospice (Figure 1). Interviews were audio taped, and a transcriptionist compiled the recordings into a written transcript. The focus was on the spoken word. No effort was made to capture features of the conversation such as nonverbal sounds, periods of silence, or emphasis on certain syllables..$^{20}$ The transcripts were reviewed for accuracy, and comments that were not transcribed correctly by the transcriptionist were added to the transcript. ${ }^{21}$

\section{Data Analysis}

The chart review, demographic information, transcripts from the interviews, and field notes were the sources of data for the analysis. Descriptive statistics were used to analyze the data acquired in the chart reviews, demographic information, and KPS scores.

Qualitative content analysis was used to analyze the interview data. ${ }^{22}$ The data-coding procedure is presented in abbreviated form here. First, after reading and analyzing the transcripts, repeated themes were identified, retrieved, and grouped for interpretation of the data. The team of researchers developed an a priori list of concepts leading to more emergent categories throughout data collection and ending with linking the concepts together to form patterns that explain the phenomena. Following Miles and Huberman ${ }^{22}$ and Cohen et al, ${ }^{23}$ the sequence of the analysis included affixing themes to a set of field notes drawn from interviews, noting reflections in the margins, and sorting to identify similar themes and finally identifying exemplars in the transcripts of the themes.

Field notes were developed for two purposes. The first purpose was to record those aspects of the interview that could not be discerned from the transcript of the tape recording: body language, tone of voice, environmental distractions, the dress and demeanor of the informant, and any important symbols in the participants' environment (eg, pictures or 
photographs, items on tables or bookshelves). The second purpose for the field notes is to provide a chance for self-evaluation. The field notes helped the interviewer with quality control and improvement of interview techniques. ${ }^{20}$ Two interviews could not be transcribed. The content of the audiotape of the first interview was unintelligible to the transcriptionist, and the second was not audio taped because of operator error. Only the field notes from those interviews were used for analysis.

\section{RESULTS}

The ages of the seven participants ranged from 53 to 87 years. Most participants were men $(n=5)$; all were ambulatory and had KPS scores of at least 70, meaning that they were very active and capable of their own self-care. Most were able to leave the home on a regular basis for activities such as attending senior day care, church, doctor's appointments, or visits with family. Three participants were enrolled in hospice, and four were under a physician's care for advanced cancer but were not enrolled in hospice or other in-home health-care. Table 1 summarizes the demographic and clinical information of the participants.

\section{End-of-Life Decisions}

The participants made multiple EOL decisions, alone and in collaboration with others (physician, nurses, family members, and caregivers). Their decisions were organized into three major types: decisions about treatment, the source of care, and communication. Treatment decisions included medical treatments, medications, and surgical or radiation therapies. Sources of care decisions included receiving care from a particular organization, facility, or hospice program. Communication decisions were defined as written or oral communication with healthcare professionals, family or friends, including the creation of advance directives and the disclosure of the diagnosis and prognosis to others. As expected, most decisions concerned medical treatment. Analysis of the transcripts revealed five themes that provide insight into factors that influence EOL decision making: (1) physician involvement in decision making, (2) family involvement in decision making, (3) quality of life, (4) religion and spirituality, and (5) communication about diagnosis and prognosis.

\section{Physician Involvement in Decision Making}

End-of-life decisions were guided primarily by clinical factors, that is, patient-related physical, emotional, and cognitive symptoms that were sequelae of the underlying disease, or medical treatments or medications used in the plan of care. ${ }^{9}$ As would be expected, the physician was the healthcare professional most likely to be involved in these decisions. The two most common decisions discussed in the interviews were those related to changing treatment when a prior therapy was not effective, that is, when a tumor was not responding to treatment or metastatic disease was detected, and halting curative treatment when all treatment options were exhausted or they would cause further harm and decrease quality of life.

One participant who was enrolled in hospice expressed regret about her decision to not seek a second opinion after her physician told her that that her colon cancer had spread to her lungs. Her physician advised her that receiving additional chemotherapy would not decrease the size of the tumor and negatively affect her quality of life. In her interview, she recounted her discussion with the hospice nurse about seeking a second medical opinion:

...I felt he gave up too soon.... [The nurse said,] "Well, if you think he gave up too soon, why don't you go and get a second opinion?" ...But then I thought about it. I don't want to go through all of that again. You know? But I always felt that the doctor should have pursued it. 
At first glance, this statement would appear to express only her anger with her physician for giving up too soon, but it also speaks to the participant's own fears and decisional conflict. She was asked why she did not follow through with seeking a second opinion, and she responded:

...The medications, like chemo, all that stuff again. I couldn't bear that. I don't want to go through it again. I think it's one half of me [wants] to do it, and the other half... the other half is saying no.... But I really, I accepted it. I accepted it.

This woman was actively involved in her care and able to provide detailed information about her treatment journey from diagnosis to the decision to stop curative treatment and seek hospice care. She also took great pride in her self-care, described as "keeping [my] body straight." It is possible that her decision to accept the doctor's prognosis might have been related to her fear that she would not be strong enough to handle the rigors of treatment rather than simply agree with the physician's plan of care. The same participant spoke of her decision to proceed with the treatment of her metastatic disease (prior to enrollment in hospice):

You are going to try everything because everybody wants to live. Everybody wants to live. So you are going to do what the doctor says.

\section{Family and Caregiver Involvement}

Social factors played a significant role in EOL decision making. Most participants had family members or caregivers who were involved in the decision making. At one end of the continuum, there were caregivers who were very involved. For example, a participant described his daughter's involvement in this manner: "My daughter... is calling the shots." She was present for discussions with the oncology surgeon and hospice staff. His daughter also signed the hospice consent and the advance directive form ("do not resuscitate" form). Another participant's daughter helped her father get organized for his appointments by suggesting that he get a large calendar that had pockets for his medication list and other information. She did not attend appointments, but would follow-up with her father and physician after her father's visits.

Two unmarried men said that they primarily made decisions without family member involvement. As they described it, family members were told about their decisions, but were not involved in the decision making. For example, one participant who was enrolled in hospice was asked whom he talked to when he was making a decision. He was quite adamant that he was an autonomous decision maker. When he was asked who he talked to, he said:

I don't need to talk to nobody-I make my own decisions. I'm not crazy for one thing.

Interestingly, after reviewing the chart and talking with the hospice manager, the man indicated that his daughter-in-law was present for the first visit by hospice. At that visit, the hospice staff member was sent away because the patient and family thought the admission was too soon and the patient was not sick enough for hospice. The clinical note appeared to contradict the patient's assertion that he made his own decisions.

A major source of conflict for another participant who was enrolled in hospice was that her physician did not ask her to bring family to the office visit when hospice was discussed. During her interview, she talked about her anger at his demeanor and the fact that he failed to include her family. There was a strident quality in her voice as she narrated the story of that day. Her anger may have covered a multitude of emotions including fear, vulnerability, 
and her belief about the importance of including her family members in decision making.

Her own mother had been enrolled in hospice at the time of her death. She said:

How can this doctor stay so cold and tell me to contact hospice? Why didn't he wait to get my family together, you know, and let's discuss this about your mother, about hospice.

She talked about the questions from her children about the decision to end curative treatment. Her daughter and son asked her about seeking a second opinion; however, the patient and family ultimately proceeded with the course of treatment that the physician had suggested: in-home hospice care.

\section{Decision Making and Individual Factors}

Each person determines the criteria used to evaluate quality of life, to define a meaningful existence, and to guide decision making. ${ }^{10}$ The participants determined the impact of cancer treatment on their lives by describing visible physical changes, such as weight loss, alopecia, decreased ability to drive at night, and difficulty maintaining their lawns and gardens. They also compared their current situation with that of other people who had received treatment for cancer and used their own definitions of "sickness." One participant said, "I'm not physically sick right now," a number of times over the course of the interview, although it was clear in the transcript and field notes that he was having physical changes related to his illness and had modified his lifestyle. For example, he was no longer able to work in his yard, he had decreased his driving at night, and he reported a decrease in appetite. His declaration, "I'm not physically sick right now," guided his decision making. When hospice staff initially came to the home to enroll him in the program, he sent them away because he did not think he was sick enough. He limited the type of equipment that the hospice staff brought to the home until he felt that he needed it.

One participant declined additional surgery for his lung cancer. He eloquently described his rationale for declining additional surgery because it would not have extended his life. What he remembered from the conversation with the oncology surgeon was "[the surgery] wouldn't prolong nothing...," "It wouldn't put 3 months on your life." He said he would have considered the surgery if he had a major physical change. He was asked to clarify what it would take for him to consider having additional surgery, he said, “....if I was feeling bad... I know I would.”

\section{Religion and Spirituality}

Religion and spirituality are individual factors that may influence EOL decision making. Religion and spirituality were discussed in many interviews. A participant who talked about his use of prayer was asked how it was used to help him in decision making. He said in his interview:

Interviewer: This decision to be in hospice-is that something that you prayed over?

Patient: Not really - they recommended what they would do and I appreciated that somebody would come to see about me.

In contrast, another participant said that his faith gave him the strength to continue with monthly physician follow-up and laboratory testing. He stated:

The Lord, yeah, the good Lord. I'm putting it in His hands. He made one step, make two, you know, he make one step and then two, I'm going to hang on in there. Yes, ma'am, I'm not going to give up for I know that he can cure everything. 
He can cure it, you know, more than the doctors know, so I'm not going to give up the faith.

\section{Communication About EOL Decisions and Disclosure of Diagnosis}

Participants made choices about the methods to communicate EOL decisions to others or to create a plan for the care of a child after their death. Most participants had an advance directive such as a state-approved "do not resuscitate" form and appointment of a healthcare surrogate. One participant, who was a widower, designated a guardian for his teenaged son.

Another participant, who was a widow living in the home of a devoted family friend who was her care-giver, had no children, and her living siblings were not actively involved in decision making. Although she did not recognize the term "advance directive," she revealed that her caregiver signed her consents for radiation therapy. The transcripts did not indicate any other role for the caregiver in decision making other than signing consents.

Disclosure of the diagnosis and prognosis to others is an important EOL decision, while a family member's or caregiver's participation and evaluation of the plan of care may be perceived as a significant source of support for the cancer patient. ${ }^{1,2}$ On the other hand, patients may limit disclosure of their diagnosis and prognosis for fear of being perceived as a burden, that talking about the illness and life expectancy may hasten death or lead to a loss of social support. ${ }^{1,2,24}$

Some participants freely disclosed their diagnosis, and others chose to reveal the diagnosis only to close family members. A participant who was not enrolled in hospice freely shared her diagnosis with people who asked about her life. She was an active member of her senior center and had also shared her illness journey on a local TV station. She admitted that she enjoyed the attention. During her interviews, she spoke of her illness journey in the context of her life story and would often switch from discussing her current illness to telling stories from her past. She knew she was very ill, but never discussed a limited life expectancy in her interviews or described herself as "dying."

On the other hand, another participant who was enrolled in hospice was reticent to disclose her prognosis. She shared her prognosis with her family, but not her friends. She explained her decision to limit disclosure to her family:

...I haven't told anyone. Just my family. I don't feel like I need to tell [inaudible], I got a year to live...

Sharing with her family had provided her support and helped her to reconnect with her daughter. Both of her children were initially shocked by the diagnosis, and although they questioned the pronouncement that "there is nothing more that can be done," they did not pressure her to seek a second opinion. The decision to tell her children was a watershed moment. Once she revealed information to her daughter, the daughter made plans to move back home to support her mother. She described her daughter's return thus:

...I didn't have my children with me. So when I got sick, I called her. So she gave up everything... and came... and she's been here ever since.... If I hadn't gotten ill, she would still be... doing her thing.... But the Lord—he called her at the right time.

Once her daughter moved back to town, she was involved in the decision to create an advance directive and received the support of the hospice social worker. The choice to not reveal to people outside the family, however, may have isolated her from emotional support from her friends. 


\section{DISCUSSION}

This study explored the individual, clinical, and social factors impacting decisions about EOL care by African Americans diagnosed with advanced cancer. Analysis of the transcripts revealed five themes that provide insight into factors that influence EOL decision making: (1) physician involvement in decision making, (2) family involvement in decision making, (3) quality of life, (4) religion and spirituality, and (5) communication about diagnosis and prognosis.

\section{The Physician's Role: "Doing What the Doctor Says"}

End-of-life decisions in the current study were guided primarily by clinical factors. Patients, caregivers, and families were involved to some extent in decision making; however, the physician had the primary role as decision maker. In the present study, the participants followed the recommendations of the physician, but not without personal reflection about the impact of the decisions on their lives. One participant who was referred to hospice considered seeking a second opinion, but did not follow through with it. She waited a month before she enrolled in hospice. Another participant agreed with physician's recommendation to not pursue further treatment because it would not help him to live longer. We saw few instances of decisional conflict, defined as a state of uncertainty about treatment options s $^{25,26}$ or a disagreement (ie, between the patient/family and physician, between patient and family/ caregivers, or even between family members) about a course of action. ${ }^{27}$

Drought and Koenig, ${ }^{28}$ who wrote about the primacy of the medical model in EOL decision making, questioned the concept of "choice" in EOL decision making. That is, although the word choice is frequently used when decision making is discussed, most patients and family members do not have the expertise of the physician or the ability to really consider treatment outcomes over the trajectory of an illness. Treatment outcomes are not always easily quantified or understood by patients and their caregivers, and therefore, they rely heavily on the physician to guide them through the process based on the physician's knowledge rather than patient's/family member's understanding of the prognosis or treatment outcomes. ${ }^{6}$ Even for racially or ethnically diverse groups making EOL decisions, there is a preference for shared involvement in decision making between patients and physicians. 5,27,29

\section{Family Role in Decision Making}

In the current study, the involvement of the family or caregivers in decision making varied, depending on availability, geographic proximity, and the health condition of the caregivers. For example, one participant's daughter lived about 200 miles from her mother, but what really affected her involvement in her mother's care was the daughter's substance abuse. Once her daughter was clean and returned home, she became actively involved in decision making. Some participants had adult children who were actively involved (ie, "calling the shots"), yet participants with family declared they were making their own decisions.

The failure of the physician to include the family in the discussion about ending curative care and enrolling in hospice was a source of emotional distress in one of situations described by a participant in the current study. Family participation in decision making is highly valued by many families. ${ }^{1,12,28}$ It may seem simplistic to talk about the importance of including the family in decision making. However, most studies that have developed or tested decision-support interventions have focused on the individual removed from the family context. ${ }^{30}$ The concept of a single decision maker, which is the hallmark of the US informed decision-making model, may not be consistent with the decision making done by all people who are making healthcare decisions. ${ }^{15}$ 


\section{Influence of Individual Factors}

The literature suggests that African Americans will pursue aggressive EOL care regardless of how the quality life might be affected. ${ }^{1,11,31,32}$ Although the interpretation of the results is limited by the small sample size, the current study demonstrates that African Americans with advanced cancer had their own metric for determining the impact of treatment on their lives and making EOL decisions such as enrolling in hospice or declining surgery, but they did not blindly follow the physician's orders. Two participants declined cancer-related treatments that were offered. Similarly, Campbell ${ }^{3}$ found that rural-dwelling African American elders with life-limiting illnesses used narratives as a strategy to help them weigh the costs and benefits of certain treatments during the decision-making process. The narratives in Campbell's study provided descriptions of poor quality of life such as being confined to bed, limitations on activities of daily living, and not being able to perform meaningful work, such as running the family farm.

\section{Religion and Spirituality}

Religion and spirituality have been identified as a significant source of support and solace in the lives of African Americans. ${ }^{1,3,32}$ In the current study, while religion and spirituality were a topic in many interviews, their influence on decision making varied. Participants spoke about the use of prayer, attending church, and reflections on specific passages in the Bible as a source of succor, but only one participant directly linked religious belief or activities with decision making. Consistent with findings in the current study, Conner ${ }^{5}$ found that religion and spirituality were a source of support for African American caregivers of patients in the advanced stages of cancer and other chronic illnesses, but it was not clear how religion and spirituality supported their decision making.

\section{LIMITATIONS}

The current study had four major limitations. First, by their very nature, EOL topics are generally hard to discuss, ${ }^{5}$ and therefore, one of the major challenges to the validity of EOL research studies is the recruitment and retention of participants. ${ }^{14,32} \mathrm{We}$ found that it was very difficult to recruit participants for this research study. However, once they enrolled in the study, we lost no participants due to attrition. The small sample size limits our ability to fully describe factors that impact EOL decision making for African Americans with advanced cancer. Barriers to the recruitment of African Americans in EOL research include long-standing issues of mistrust between the African American community and the healthcare system, ${ }^{33,34}$ misunderstanding about the role of hospice care in the cancer trajectory, $1,2,5$ and ethical concerns about the participation of people with a life-limiting illness in research. ${ }^{15}$ During community outreach activities to discuss the study, we frequently heard of stories of the poor treatment that African Americans had received in healthcare institutions, including the university teaching hospital. Hospice providers were reluctant to participate as clinical sites for the study because of fear that their relationship with African American families could be jeopardized if there were complaints about the study.

Second, participants in this study demonstrated fairly high functional status scores (KPS total scores ranged from 70-90), that is, having the ability to perform activities of daily living, working outside the home, and seeking medical care for regularly scheduled appointments. The higher the KPS score, the better the functional status (scores range from $0-100) .{ }^{17}$ Younis and colleagues ${ }^{35}$ studied hospice patients with advanced cancer and found that $46 \%$ of patients had a median KPS score of 50 or less. A KPS score of 50 indicates that an individual requires considerable assistance with activities of daily living and frequent medical and nursing attention, including home-based care. If our participants had a poorer 
functional status (ie, had been more ill), we might have captured other decisions common to the latter part of the trajectory of advanced disease such as initiating artificial nutrition or intravenous fluids or the withdrawal of those treatments.

Third, we interviewed people after a major decision making was completed (sometimes a year or more later). End-of-life decision making really is a process that occurs over a period. It is a series of decisions: changing chemotherapeutic agents, stopping anticancer treatment, considering palliative treatment, and/or choosing hospice. We may have not captured the intense emotion-laden nature surrounding many aspects of EOL decision making. More descriptions of decisional conflict may have appeared in the transcripts if the interviews had been conducted during the process of active decision making.

Finally, we also did not collect information from family members or HCPs who were involved in decision making. Having the perspective of family members or HCPs would have contributed more insight into the experience of EOL decision making, including decisional conflict. The data analysis of the interview transcripts did not reveal patientfamily or family-physician conflict about decision making.

\section{Implications for Practice and Research}

The findings from this pilot study have two significant nursing implications for clinical practice. First, if informed patient choice is a standard of practice, patients and their families and caregivers must be provided with time to discuss not only the clinical issues, but also how cancer and cancer treatment impact quality of life. Second, social factors heavily influence EOL decisions. A person's physical, emotional, or cognitive capacity may require the addition of other decision makers, such as family members, ${ }^{12}$ a close friend, a life partner, or a formally appointed healthcare surrogate. ${ }^{36,37}$ Significant people (as defined by the patient) must be involved in decision making in person, by phone, or by using telemedicine connections and other technology.

Future studies of factors that impact decision making should include family members, caregivers, and health-care professionals. Each perspective would offer variations on decision making that could lead to interventions to support patients, family members, caregivers, and healthcare professionals.

Moreover, family members should be involved in the testing of decision-support interventions, such as decision aids. Given that religion and spirituality have been identified as strength of African Americans, future research studies should also explore the role of religion and spirituality in EOL decision making.

The small sample size limited our ability to interpret results and to provide a meaningful description. Research teams that are focusing on EOL care in racial/ethnic minority communities must incorporate culturally competent research strategies for community outreach, recruitment, and retention.

\section{Acknowledgments}

This article was supported in part by Rural Health Care Research Center, from the National Institute of Nursing Research (grant P20 NR009009). Additional support was provided by Roberts Scholars Program from the University of Virginia and the American Nurses Foundation/Gloria Smith and Eleanor Lambertson Award Scholar grant (to Dr Campbell). 


\section{References}

1. Payne, R.; Armstrong, T.; Johnson, K.; Robinson, U. A Progressive Palliative Care Educational Curriculum for the Care of African Americans at Life's End (APPEAL). Durham, NC: Duke Institute on Care at the End of Life; 2010.

2. Taxis C. Attitudes, values, and questions of African-Americans regarding participation in hospice programs. J Hosp Palliat Care Nurs. 2006; 8(2):77-85.

3. Campbell C. Keeping faith. J Hosp Palliat Care Nurs. 2007; 9(1):31-41.

4. Flory J, Yinong XY, Gurol I, Levinsky N, Ash A, Emanuel E. Place of death: U.S. trends since 1980. Health Aff. 2004; 23(3):194-200.

5. Conner, N. End-of-life informal caregiving and decision-making experiences among blacks. Paper presented at the Annual Meeting of the Southern Nursing Research Society; February 12-14, 2009; Baltimore, MD.

6. Weiner J, Roth J. Avoiding Iatrogenic harm to patient and family while discussing goals of care near the end of life. J Palliat Med. 2006; 9(2):451-463. [PubMed: 16629574]

7. Murray MA, Fiset V, Young S, Kryworuchko J. Where the dying live: a systematic review of determinants of place for end-of-life care. Oncol Nurs Forum. 2009; 36(1):69-77. [PubMed: 19136340]

8. Gauthier D. Decision making near the end of life. J Hosp Palliat Care Nurs. 2005; 7(2):82-90.

9. Bender C, Ergun F, Rosenzweig M, Cohen S, Sereika SM. Symptom clusters in breast cancer. Cancer Nurs. 2005; 28(3):219-225. [PubMed: 15915067]

10. Frankl, VE. Man's Search for Meaning. New York: Pocket Books; 1985. p. 121-123.p. 138

11. Winston CA, Leshner P, Kramer J, Allen G. Hospice and palliative care services in African American communities. Omega. 2005; 50(2):151-163. [PubMed: 16021737]

12. Mehta A, Cohen SR, Chan L. Palliative care: a need for a family systems approach. Palliat Support Care. 2009; 7:235-243. [PubMed: 19538807]

13. Hospice and Palliative Nurses Research Association. Hospice and Palliative Nurses Association 2009-2012 Research Agenda. Pittsburgh, PA: Hospice and Pallative Nurses Association; 2008.

14. Ransom S, Azzarello L, McMillan SC. Methodological issues in the recruitment of cancer pain patients and caregivers. Res Nurs Health. 2006; 29:190-198. [PubMed: 16676340]

15. Campbell C. Respect for persons: engaging African Americans in end-of-life research. J Hosp Palliat Care Nurs. 2007; 9(2):74-78.

16. Campbell C, Merwin E, Yan G. Community characteristics that predict whether a rural community has one or more Medicare-certified hospices. J Nurs Scholarsh. 2009; 41(4):420-428. [PubMed: 19941588]

17. Karnofsky, DA.; Burchenal, JH. The clinical evaluation of chemotherapeutic agents in cancer. In: MacLeod, CM., editor. Evaluation of Chemotherapeutic Agents. Symposium, Microbiology Section, New York Academy of Medicine. New York, NY: Columbia University Press; 1949. p. 191-205.

18. Mor V, Laliberte L, Morris J, Wieman M. The Karnofsky Performance Status Scale: an examination of its reliability and validity in a research setting. Cancer. 1984; 53:2002-2007. [PubMed: 6704925]

19. Yates J, Chalmer B, McKegney FP. Evaluation of patients with advanced cancer using the Karnofsky Performance Status. Cancer. 1980; 45:2220-2224. [PubMed: 7370963]

20. Patton, M. Qualitative Evaluation and Research Methods. 2. Newbury Park, CA: Sage; 1990.

21. Sandelowski M. Focus on qualitative methods: notes on transcription. Res Nurs Health. 1994; 17:311-314. [PubMed: 8036279]

22. Miles, M.; Huberman, AM. Qualitative Data Analysis. 2. Thousand Oaks, CA: Sage; 1994. p. 55-89.

23. Cohen, MZ.; Kahn, DL.; Steeves, RH. How to Analyze Data. Thousand Oaks, CA: Sage; 2000. Hermeneutic Phenomenological Research: A Practical Guide for Nurse Researchers; p. 71-92. 
24. Lannin D, Mathews H, Mitchell J, Swanson MS, Swanson FH, Edwards MS. Influence of socioeconomic and cultural factors on racial differences in late-stage presentation of breast cancer. JAMA. 1998; (22):1801-1807. [PubMed: 9628711]

25. O'Connor, AM. Decisional conflict. In: McFarland, GK.; McFarlane, EA., editors. Nursing Diagnosis and Intervention. 3. Toronto, ON, Canada: CV Mosby; 1997.

26. Song M, Sereika SM. An evaluation of the Decisional Conflict Scale for measuring the quality of end-of-life decision making. Patient Educ Couns. 2006; 61:397-404. [PubMed: 15970420]

27. Zhang A, Siminoff $\mathrm{L}$. The role of the family in treatment decision making by patients with cancer. Oncol Nurs Forum. 2003; 30(6):1022-1028. [PubMed: 14603359]

28. Drought TD, Koenig B. "Choice" in end-of-life decision making: researching fact or fiction. Gerontologist. 2002; 42(special issue III):114-128. [PubMed: 12415142]

29. Caralis PV, Davis B, Wright K, Marcial E. The influence of ethnicity and race on attitudes toward advanced directives, life-prolonging treatment and euthanasia. J Clin Ethics. 1993; 4(2):155-165. [PubMed: 8334279]

30. O'Connor AM, Stacey D, Entwistle V, et al. Decision aids for people facing health treatment or screening decisions. Cochrane Database Syst Rev. 2003; 1:art. no. CD001431.

31. Borum ML, Lynn J, Zhong Z. The effects of patient race on outcomes in seriously ill patient in SUPPORT: an overview of economic impact, medical intervention, and end-or-life decisions. J Am Geriatr Soc. 2000; 48(5):S194-S198. [PubMed: 10809475]

32. Williams A. Recruitment challenges for end-of-life research. J Hosp Palliat Care Nurs. 2007; 9(2): 79-85.

33. Barrett RK. Dialogues in diversity: an invited series of papers, advance directives, DNR's and endof-life care for African Americans. Omega. 2005-2006; 52(3):249-261.

34. Campbell L, Keefe F, Scipio C, et al. Facilitating research participation and improving quality of life for African American prostate cancer survivors and their intimate partners. Cancer. 2007; 109(S2):414-424. [PubMed: 17173280]

35. Younis T, Milch R, Abul-Khoudoud N, Lawrence D, Mirand A, Levine E. Length of survival in hospice: a retrospective analysis of patients treated at a major cancer center versus other practice settings. J Palliat Med. 2007; 10(2):381-389. [PubMed: 17472510]

36. Casarett D, Karlawich J, Morales K, Crawley BA, Mirsch T, Asch DA. Improving the use of hospice services in nursing homes: a randomized clinical trial. JAMA. 2005; 294:211-217. [PubMed: 16014595]

37. Meeker M. Family surrogate decision-making at the end-of-life: seeing them through with care and respect. Qual Health Res. 2004; 14(2):204-225. [PubMed: 14768458] 
1. Please tell me about your decision to accept hospice care or [other choice i.e. continuing with chemotherapy].

\section{Possible follow-up question}

How did you find out about hospice or [other choice]?

2. Describe what influenced your decision

Possible follow-up question (s)

Something you heard from: Physician? Other Health Care Provider? Services offered by hospice? How you were feeling? Change in your symptoms? Ability to care for yourself? Religion/Spiritual belief or other personal belief?

3. When you want to make a decision, who do you talk to? What other help do you seek to make decisions?

4. What help did you seek to make the decision to be in hospice or [other choice]?

5. What have your___ [family, caregivers, friends, church members ] said about your choice of

Figure 1.

A selection of questions from the interview guide. Adapted from the Journal of Hospice and Palliative Care Nursing. ${ }^{8}$ 


\section{Table 1}

Demographic Information

\begin{tabular}{|lclcc|}
\hline Cancer Type & Age, $\mathbf{y}$ & Sex & Marital Status & KPS Score \\
\hline Lung & 79 & Female & W & 80 \\
Colon & 65 & Female & D & 90 \\
Prostate & 74 & Male & D & 80 \\
Lung & 87 & Male & M & 70 \\
Multiple myeloma & 68 & Male & S & 80 \\
Lymphoma & 70 & Male & W & 70 \\
Multiple myeloma & 53 & Male & M & 70 \\
\hline
\end{tabular}

Abbreviations: D, divorced; M, married; S, single (never married); W, widowed. 